\title{
Perspectives regarding disproportionate representation of culturally and linguistically diverse students in high-incidence special education programs in the United States
}

BACKGROUND

The number of culturally and linguistically diverse students in the U.S. is growing, and research shows they are often underassessed, misdiagnosed, and placed into special education unnecessarily. This problem mainly concerns high-incidence, or judgmental, disabilities such as learning disability, emotional disturbance, or mental retardation.

\section{PARTICIPANTS AND PROCEDURE}

In this study, the author examines how some educators perceive and address culturally and linguistically diverse students in the U.S. A survey developed by the author was used to examine how educators perceive culturally and linguistically diverse student populations and how one Midwestern school system in the United States dealt with culturally and linguistically diverse students' needs versus expected ideal practices.

\section{RESULTS}

Results indicated that most participants recognized that the issue of disproportionate representation is nationwide, but did not believe that their district shared that problem.

\section{CONCLUSIONS}

Participants indicated that best practices were not being followed maximally to reduce and avoid the problem of disproportionate representation of culturally and linguistically diverse students in special education programs. Difficulties in meeting students' needs may be related to cultural differences that school personnel are unable to assess or address. Recommendations include suggestions for further studies and for applying the survey in other school systems to increase the understanding and improve their practice in working with culturally and linguistically diverse students.

\section{KEY WORDS}

culturally and linguistically diverse students; minority students; special education; disproportionality 


\section{BACKGROUND}

To appreciate the scope and implications of the phrase "culturally and linguistically diverse" (CLD) it is helpful to isolate and define its respective elements. "Immigrants" and "linguistically diverse persons" do not have synonymous meanings, though they are often used interchangeably. Immigrants come from a different country, which does not necessarily imply that they do not know English, either as a first or second language. Linguistically diverse persons possess knowledge of a language other than the mainstream language (Perez, 1998); however, they may or may not be immigrants (Nieto \& Bode, 2008). Culturally diverse persons come from an ethnic and cultural background other than the mainstream and differ in their ethnicity, social class, and/or language (Perez, 1998, p. 6).

In this research study, the term "culturally and linguistically diverse" is the designate for people who were born and/or raised in different cultures, or who were born and/or raised in the United States but live under the heavy influence of another culture and speak only their native language or their native language and English. In this research, other terminology is used only when specifically referring to such populations (e.g., English language learners - ELL), as distinct from CLD in general, or when it is quoted from a work that uses such a term.

\section{CULTURALLY AND LINGUISTICALLY DIVERSE STUDENT ISSUES}

The population of the U.S. is becoming ever increasingly diverse. Over 380 different languages are spoken in the United States (Shin \& Kominski, 2010), with over 57 million people regularly using these different languages, according to the 2009 Census (Aud et al., 2011). The National Center for Education Statistics cites an increase in school-aged children speaking a language other than English at home, from 4.7 million in 1980 to 11.2 million in 2009 (Aud et al., 2011), which indicates a population increase from $10 \%$ to $21 \%$ in these respective years.

Providing successful educational experiences as well as psychological and counseling support to diverse students presents complex challenges to our educational system (Artiles \& Ortiz, 2002), as these students may face obstacles specifically due to their cultural and linguistic diversity (Park \& Thomas, 2012). It is further problematic when schools under-recognize the sources of these challenges, and misguidedly reach out to special education programs for assistance with these students. Similarly, it is problematic when CLD students are delayed in being given the appropriate linguistic support they need because of this misdirection.
Substantial research demonstrates uneven representation of minority students in various programs (Brown, 2007; Artiles et al., 2010); significantly, culturally and linguistically diverse students comprise a subgroup of students that is disproportionately represented in special education programs. According to Warger and Burnette, "More minority children are served in special education programs than we would expect based on their percentage in the general school population" (2000, p. 1). The Office of Special Education Programs (OSEP) and the Office for Civil Rights (OCR) have reported the imbalance in the representation of minority students in special education (Burnette, 1998; Rueda \& Windmueller, 2006). Disproportionate representation of minority groups, including English language learner (ELL) students - an attribute of a subset of CLD students - in special education is an issue documented for more than 40 years (Sullivan, 2011; Rueda \& Windmueller, 2006) in the United States. Typically, CLD students are overrepresented in high-incidence disabilities (i.e., specific learning disability, emotional disturbance) and underrepresented in programs for gifted and talented students (Artiles, Rueda, Salazar \& Higareda, 2005). Sullivan (2011) noted a paradoxical pattern of overrepresentation and underrepresentation of ELL students in the U.S. due to underreferral and overdiagnosis. Consequently, educational opportunities are limited for students who are not native, or whose parents are not native, to the dominant culture.

An emerging trend also indicates that ELL students are underrepresented in special education in the primary grades but overrepresented beginning in the third grade (Samson \& Lesaux, 2009). In a study conducted by Sullivan (2011) in a southwestern school district educating over 1 million students, it was found that in the specific learning disability (SLD) category, students went from being $24 \%$ more likely to be identified in 1999 to $82 \%$ more likely in 2006 (Sullivan, 2011).

It has also been well documented in academic literature that African American students historically have been overrepresented in programs for students with mental retardation and emotional disturbance (Skiba et al., 2006; Sullivan, 2011). Shifrer, Muller and Callahan (2011) have presented evidence indicating that African American students have been increasingly identified since the 1970s in the learning disabilities categories at rates higher than their Caucasian counterparts. According to OSEP statistics from 2007, American Indians or Alaskans were 1.8 times more likely and Hispanic children were 1.1 times more likely to be diagnosed with specific learning disabilities (SLD) (Shifrer et al., 2011). Obringer (1998), Skiba et al. (2006), and the Illinois State Board of Education (2007) each developed independent statewide studies that demon-
Perspectives on disproportionate representation 
strated minority imbalances in special education programs. For instance, in Obringer's (1998) work, there were defined imbalances in the number of African American students represented by the Mississippi public school districts, which resulted in $24 \%$ of that African American student population being part of special education programs, though they represented only $14 \%$ of the overall student population. In addition, Skiba et al. (2006) found that the State of Indiana fared no better. The disproportionate representation in the SLD category is a central problem in the spectrum of disproportionate identification in other special education categories (Shifrer et al., 2011).

Overrepresentation in special education should serve "more as a warning sign of a host of more basic issues to address rather than as the sole problem requiring attention. The primary concern should be the need for services, quality of instruction and ultimately academic and life outcomes" (Artiles \& Rueda, 2002, p. 6). Disproportionate representation in special education programs of CLD students is due, at least in part, to schools' meager understanding of CLD students, which is reflected in inadequate classroom practices and support, underused referral systems for struggling CLD students, inconsistent assessment practices (Park \& Thomas, 2012; Shepherd, Linn \& Brown, 2005), and ineffective collaboration of staff. The greatest challenge rests in the high-incidence disabilities, where professional judgment plays a significant role in the identification process. According to Reschley (1996), "of all disability categories, mild learning disability may be the most difficult to diagnose" (p. 6).

The purpose of the current study was to investigate factors that contribute to this disproportionate representation of CLD students in special education programs, and to improve understanding of this issue by examining elements such as school practices and viewpoints associated with this disproportionate representation. The research further includes recommended best practices to avoid disproportionality in special education, reduce or avoid special education imbalances and serve as a roadmap to ensure successful education for CLD students.

To determine if a school is able to recognize the need for additional best practices, it is necessary to examine their institutional intent and ability to assess, recognize, and respond to variations in classroom or student needs. The researcher developed and conducted a survey to determine to what extent surveyed participants self-reported that (1) current practices reflect the ideal practices among school personnel as reported by surveyed participants; and (2) their perceptions of culturally and linguistically diverse students' representation in special education including ways to avoid disproportionate representation.

\section{PARTICIPANTS AND PROCEDURE}

This study integrated a quantitative research method guided by descriptive research methodology with between-participants design approach and the use of survey research. Recommended practices in the survey research domain formed the basis for the survey questionnaire development to increase the validity of this instrument and decrease bias.

The survey was designed to apprise current practices in surveyed schools as well as participants' perceptions with regard to best practices for CLD students. Multiple items on many constructs were created to further increase the reliability of the instrument (Garson, 2007). Model, control, and crosscheck items were incorporated into the survey: model items were intended to measure variables; control items (i.e., age, race, gender) were used to "determine if model relationships are controlled, modified, or rendered spurious by virtue of other variables (control variables)" (Garson, 2007, p. 6); and crosscheck items were used as an internal check to test consistency with other responses (Garson, 2007).

\section{SETTING AND SAMPLE}

Participants were selected from a school district of an urban county in a Midwestern U.S. state with a population of approximately 5.3 million people (ePodunk. com, 2008) composed of culturally and linguistically diverse communities; specifically, $19 \%$ of the population were Hispanic or Latino of any race, $9 \%$ were of Polish, $11 \%$ German, 10\% Irish, and 6\% Italian ancestry (ePodunk.com, 2008). The selected district's total population was around 84,000 , including nearly 43,000 individuals of White and 40,000 of other races. Persons of Hispanic or Latino origin (of any race) accounted for 72,000 of the community (Census Viewer, 2010).

The district educates nearly 8,000 students, $8 \%$ of whom are White, 4\% African American, 86\% Hispanic, $1 \%$ Asian/Pacific Islander, $0.1 \%$ Native American, and less than 1\% multiracial (DataCenter, 2012). The teacher body is composed of nearly $87 \%$ White, 1\% African American, 10\% Hispanic, and 2\% Asian/ Pacific Islander (DataCenter, 2012). Surveyed participants included school administrators, teachers, and student support practitioners - a category that includes school psychologists, school social workers, and school counselors.

\section{PARTICIPANT CHARACTERISTICS}

Out of the 144 respondents to the survey, $87 \%$ were Caucasian, 2\% African American, 11\% Hispanic, and $1 \%$ "Other". Nearly two-thirds of participants (65\%) 
did not speak a second language. Of the respondents, $78 \%$ were teachers, and $22 \%$ either administrators or student support practitioners. Thus, the respondents did not display the same diversity levels as those of the community (and presumably, by extension, their students); however, this is not unusual for school districts.

\section{RESULTS}

\section{PROFESSIONAL ROLES}

This distinction was included due to the importance of understanding the relationship between the participants of the survey and their customary interaction with students, potentially those with CLD needs. As expected, the largest respondent group was regular education teachers since they typically make up the largest percentage of employees in any school district. Participants in this study totaled approximately $62 \%$ regular education teachers, $15 \%$ special education teachers, $15 \%$ psychologists, counselors and other student support practitioners, $5 \%$ administrators, and 3\% bilingual/ESL teachers.

\section{LIMITATIONS}

This survey only examined the staff of one school system; while the results are applicable for use by this district, the study is not intended to create overall generalizations for other systems. This information can be used to develop studies within other school districts, build relationships between current best practices and needs assessments, and can be examined for other underlying causes of CLD imbalances. Complexity issues of using singular results as a broad definition over many schools is also found in the calculation criteria. Some school districts may be bilingual districts, as is found in Texas or California, in which school correspondence may consistently be developed to serve both English- and Spanish-speaking families. In that example, results may differ about ideal versus current practices. Also, because it is most common for schools to divide students into English language learner categories, rather than CLD groups, it may be essential to address whether educators or related staff are familiar with the terms of CLD before developing a study to address suspected issues.

\section{PERCEPTIONS OF CURRENT PRACTICES VS. IDEAL PRACTICES FOR CULTURALLY AND LINGUISTICALLY DIVERSE STUDENTS}

Several questions of the survey asked participants to report about current and ideal practices in their school district in the area of distinguishing characteristics of disability, collaboration, team involvement in the pre-referral and referral processes for CLD students, and problem solving approaches to determine to what extent current practices reflect the ideal practices as reported by surveyed participants. Table 1 represents respondents' choices:

- Nearly $90 \%$ of respondents reported that the school should ideally always distinguish the characteristics of a disability from cultural differences, while only one-fourth of respondents felt that this was currently the practice.

- The highest percentage (42\%) of respondents for current practices indicated that they usually use staff collaboration to provide multiple perspectives on a student's difficulties. However, three-fourths of respondents felt that this should ideally always be the practice. As a current practice, only $11 \%$ of respondents felt that their school always uses staff collaboration to extend each teacher's collection of instructional strategies. Almost two-thirds responded that the school should always use this practice.

- Close to $80 \%$ of respondents felt that use of joint problem solving when students are struggling academically or behaviorally should always be the practice; however, less than one-quarter of them felt that this practice was always used within their schools. Over half of the participants selected the response that usually this is the current practice.

- For responses to the survey question about having a pre-referral process or team that works with teachers prior to making special education referral, a broader variety of answers were selected and a higher percentage of respondents did not know: $21 \%$ for current practices, and about $7 \%$ for best practices. Nearly one-third of respondents felt the school currently always used this practice, and over $80 \%$ felt they should always use this practice.

- For responses regarding the use of a response to intervention model as a problem solving approach, a larger percentage of respondents (under 20\%) did not know if they agreed that their school uses a response to intervention model to help struggling students; around 7\% of respondents did not know if ideally such practice should be in place. Additionally, nearly $80 \%$ said that the school should ideally always practice this usage, while only $11 \%$ felt the school always does in current practice.

\section{PERCEPTIONS OF CULTURALLY AND LINGUISTICALLY DIVERSE STUDENTS' REPRESENTATION}

Another set of questions on the survey was meant to examine the extent to which survey participants self-reported their perceptions of CLD students' representation in special education and ways to avoid
Perspectives on disproportionate representation 


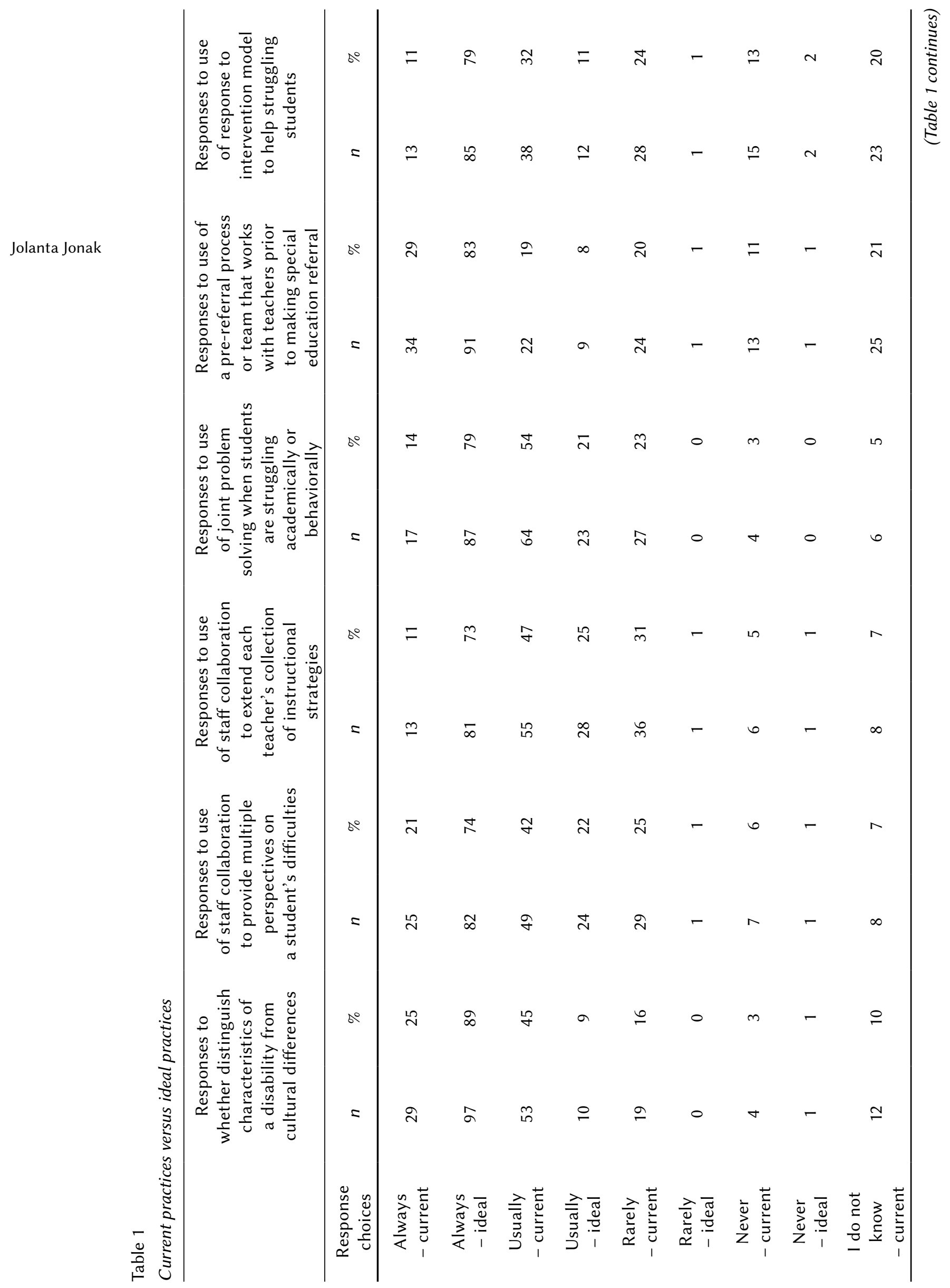




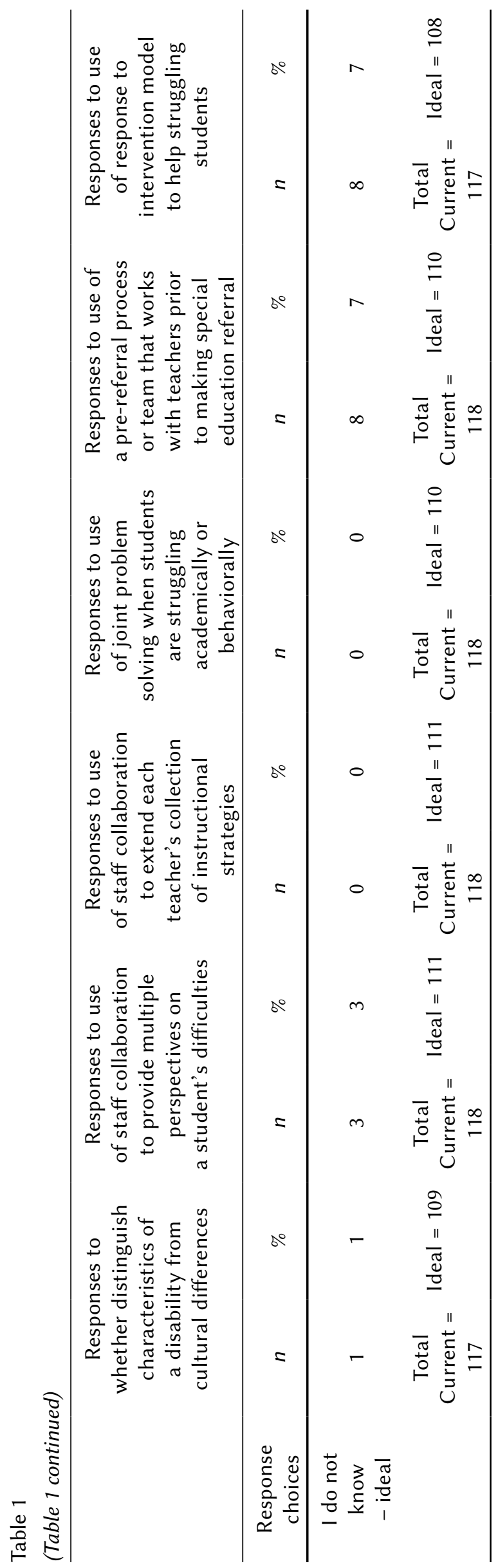

disproportionate representation. The first part of this area of the questionnaire asked if CLD students in special education programs nationally are - with answer choices of over-identified, under-identified, misidentified, and properly represented. The results were relatively similar among all options. Just over one-fourth of the respondents felt that CLD students were over-identified in special education programs, and $27 \%$ felt they were under-identified. Approximately $30 \%$ perceived CLD students as misidentified, and only $14 \%$ felt they were properly represented.

Participants were also asked about their opinions if CLD students in special education programs in their district are - allowing them to select choices including over-identified, under-identified, misidentified, and properly represented. Overall, the largest percentage of respondents felt that in their school district CLD students were properly represented $(41 \%)$. The next highest responses in order were under-identified $(32 \%)$, misidentified (16\%), and over-identified at $11 \%$ of responses.

As represented in Table 2, study participants were also asked to report how disproportionate representation of CLD students in special education could be avoided. More than two-thirds of respondents felt that schools would be assisted by discerning among second languages and assigning different resources to different second language students in order to prevent incorrect identification of the language learning process as a learning disability. Other options endorsed by $42 \%$ to $59 \%$ of respondents were: appropriate curriculum; appropriate instructional practices; multicultural education; improved pre-referral practices; professional development activities focused on CLD students; culturally sensitive school policies; family and community involvement; appropriate teacher preparation; selected use of accurate assessment instruments and appropriate assessment practices for special education eligibility; and finally, selected improved practices through response to intervention.

\section{DISCUSSION}

Regarding to what extent respondents felt that current practices reflected ideal practices, there was a discrepancy between reports on current practices versus ideal practices. Respondents overwhelmingly felt that schools should ideally always distinguish the characteristics of a disability from cultural differences; however, only one-fourth felt that this was currently the practice. Schon, Schaftel and Markham recognized that many issues were found within the educational system in reviewing "cultural bias v. cultural loading" and "language bias v. linguistic demand" (2008, p. 169). Development of effective methods for distinguishing the characteristics of a disability from cultural differences requires that the school
Perspectives on disproportionate representation 
Table 2

Responses to beliefs of how schools and school districts can avoid disproportionate representation of CLD students in special education

\begin{tabular}{ccc}
\hline Response choices & Responses & Percentages \\
Appropriate curriculum & 77 & 54 \\
Appropriate instructional practices & 76 & 49 \\
Use of multicultural education & 70 & 69 \\
and learning disability & 98 & 42 \\
Improved pre-referral practices & 51 \\
Improved practices through response to intervention & 60 & 59 \\
Use of accurate assessment instruments and appropriate & 73 & 57 \\
assessment practices for special education eligibility & 84 & 52 \\
Appropriate teacher preparation & 81 & 46 \\
Camily and community involvement & 75 & 56 \\
\hline
\end{tabular}

Note. Total $N=143$.

develop methods for recognizing the bias that may be present in the system when evaluating the students. In order to meet these needs, teams must be aware of the many CLD studies that assess the differences in cultural bias, cultural loading, language bias, and linguistic demand. A first endeavor that would successfully lead to this progress is a commitment from the school district in the form of a dedicated team with complete awareness of cultural versus disability needs. Developing practices that improve the ability of the school to differentiate between disabilities and CLD needs will increase the success rate of productively placing students in programs that will permit growth and learning. School psychologists play a particularly important role in such teams as they have the expertise to recognize disabilities, their characteristics and dispositions.

In regards to collaboration, the highest percentage (42\%) for current practices indicated that respondents usually use staff collaboration to provide multiple perspectives on a student's difficulties. However, three-fourths of respondents felt that this should ideally always be the practice. As a current practice, only $11 \%$ of respondents felt that their school always uses staff collaboration to extend each teacher's collection of instructional strategies. Almost two-thirds responded that the school should always use this practice. While it is hoped that the staff would always collaborate on the needs of students, it is reasonable to believe that at times the school may have pressing matters that prevent full collaboration. When this occurs, there is a risk that a student may be misdiagnosed and placed in the wrong environment for successful learning. For instance, Ortiz's study from 1992 found that Hispanic students who were educated in special education programs as learning disabled actually had decreased scores on IQ tests and did not improve academically after three years of receiving services. When education may actually be damaging to students due to misdiagnosis and misplacement, schools should be very serious about the use of recommended practices in the field of assessment. When schools discover that other commitments interfere with student needs, it may become appropriate to add secondary measures that can be applied to prevent long-term placement in the wrong classes.

These results represent the awareness of what should be in place and what actually happens. Table 1 also includes the results of the responses for the survey question addressing use of joint problem solving when students are struggling academically or behaviorally. Close to $80 \%$ of respondents felt that the use of joint problem solving when students are struggling academically or behaviorally should always be practiced. However, less than one-quarter of respondents felt that this practice was used within their school districts.

Schools striving to become progressive examples for other school systems will need to embrace best practices identified in many studies and typically recognized as best practices by their staff. Using joint problem solving, assessment teams, and providing educators and student support practitioners with additional resources for training will promote healthy classroom environments reflective of the best practices demonstrated in studies. 
Many organizations have begun to use teamwork to successfully address difficult needs or develop unique solutions. This method allows a number of different viewpoints to be shared from extensive knowledge as demonstrated by group collaboration among teachers, school psychologists and school counselors, increasing the overall success of meeting CLD needs.

For the responses to the survey question about having a pre-referral process or team that works with teachers prior to making special education referral, nearly one-third of respondents felt the school currently always used this practice and over $80 \%$ felt they should always use this practice. Burnette (1998) recognized that best practices for schools include use of pre-referral strategies in general education, along with proper documentation of the strategies used and their results, providing training in alternative instruction and materials, as well as in distinguishing the characteristics of a disability from characteristics that reflect cultural differences. Additionally, Burnette (1998) identified that use of joint problem solving to extend each teacher's repertoire of instructional strategies and provide multiple perspectives on a student's difficulties would increase successful learning for diverse and CLD students. School staff are further encouraged to develop programs that may avoid unnecessary assessment in the future and/ or increase the appropriate classroom activities necessary to maintain high-quality education for CLD needs.

An extension of a joint problem solving approach is an initiative called Response to Intervention (RTI). This approach is used to identify and support struggling learners. Responsiveness to interventions entail a "shift from a within-child deficit paradigm to an eco-, behavioral perspective” (NASDSE, 2006, para. 7) which is appealing to many educational advocates. Assessments in the RTI model have a purpose to assist in: (1) screening all children to identify those who are not making expected progress; (2) diagnostics to determine what children can and cannot do in academic and behavioral domains; and (3) progress monitoring to determine if interventions produced desired effects (NASDSE \& CASE, 2006).

Regarding use of a response to intervention model to help struggling students with current practices, nearly $80 \%$ said that the school should ideally always practice this usage, while only $11 \%$ felt the school always does in current practice. The relatively low percentage of responses that this was current practice may indicate that this practice is not widespread throughout the district or that the staff does not have a good understanding of what constitutes response to intervention. Furthermore, this practice was just gaining momentum at a national and state level during the time of this research, so it is possible that the familiarity with and the use of this model were limited.
Study participants were also asked about their perceptions regarding representation of CLD students in special education programs. Respondents in this study felt similarly to the results found by others that imbalances currently exist in representation of certain students in special education programs. According to the National Education Association (NEA), English language learning students are underrepresented in special education programs; however, the imbalance in cultural diversity varies greatly across the United States (NEA \& NASP, 2007). According to Keller-Allen (2006), English language learning students in school districts with small ELL populations are over-represented in special education programs at a rate of almost $16 \%$; however, they are underrepresented in school districts with ELL populations of 100 students or more, with average representation of about $9 \%$ (as cited in NEA \& NASP, 2007).

When study participants were asked to report how disproportionate representation of CLD students in special education could be avoided, more than two-thirds of respondents felt that schools would be assisted by discerning among second languages and assigning different resources to different second-language students in order to prevent incorrect identification of the language learning process as a learning disability. These responses are positive verification that further research can prevent CLD disproportional representation in special education classes.

A major finding from the results of the questionnaire regarding current and ideal practices included the differences between what the respondents believed should happen and what actually happened at their schools. Study participants indicated that selected current practices were represented in $11 \%$ to $29 \%$ on a regular basis in their schools, whereas they believed these practices should always take place in $73 \%$ to $89 \%$, depending on the practice. Thus, the largest number of survey participants demonstrated a perception of real school practices as being lower, less frequent, and less effective.

Finally, participants of the questionnaire most often agreed that there are improvements needed for CLD students within their school. A majority of respondents felt that the problem of disproportional representation was not as large within their school district as the problem that exists nationally, and most participants agreed that disproportional representation can be avoided when best practices are used. Education must assist all children in learning, regardless of race, gender, cultural background, or other distinguishing factors. Failure of the educational system can prevent children from having the requisite knowledge to become productive and successful members of society. Developing practices that improve the ability of the school to successfully educate all students will provide immediate and
Perspectives on disproportionate representation 
long-term benefits. Additionally, educators must recognize where system failures are in order to fully compensate during times of need.

\section{RECOMMENDATIONS}

Schools able to conduct surveys such as this one can better understand where educators, school psychologists and school counselors believe that problems exist in their system, elucidating comparisons and collaborations between various types of school personnel, as their perspectives may differ based on their school roles. Educators and student support practitioners must distinguish whether students' needs are due to disability or to cultural and linguistic needs. Some of this is done through the assessment of ESL or other assessments that have been created to discern between an inability of a student and a cultural need. Some risks that are present and must be taken into consideration in the evaluation process include situations such as poverty, other languages spoken at home, cultural differences, disabling conditions, or related home-life challenges. These can be overcome by careful consideration of CLD best practices.

Recommendations endorsed by this study's participants included: discerning between the language learning process and a learning disability, use of appropriate curriculum, appropriate instructional practices, multicultural education, improved pre-referral practices, professional development activities focused on CLD students, culturally sensitive school policies, family and community involvement, appropriate teacher preparation, selected use of accurate assessment instruments and appropriate assessment practices for special education eligibility, and finally, selected improved practices through response to intervention.

This study revealed that the school district may need to consider further study on how best practices can be implemented more completely and effectively. Recommendations for future study include reviewing potential training programs, supporting further examination, and developing interaction techniques for team development among educators within the district.

\section{CONCLUSIONS}

This researcher believes that the broader student teaching and support community (rather than exclusively special education) bears a great proportion of responsibility in this issue and that a comprehensive and inclusive approach to educating CLD children is needed to eliminate inappropriate assignment to special education programs and avoid the disproportionate representation of CLD students in special education, especially in the high-incidence programs.
Best practice recommendations will enable schools to successfully avoid imbalances in CLD needs within their systems. To solve the issue of disproportionate representation of CLD students in educational programs, general education, student support practitioners and special education are collectively responsible. The examination and improvement of practices in both fields is imperative to create an educational environment conducive for CLD students' learning, which in turn prevents inappropriate special education placements.

Each professional in the education community has a responsibility to remain current in information needed to address student needs and requirements; however, many CLD needs are not recognized core objectives of districts. Education professionals must feel confident in their ability to handle the needs of CLD students and when they do not, they must be able to find answers to their problems on their own. Teams must be developed in schools in order to assist teachers in recognizing needs or interacting with the students demonstrating CLD needs. The discussed problems and highlighted practices may not be unique to this one school district. It was noticeable that other studies produced similar findings to the findings of this study. This can serve as a guide to other educational systems to be proactive in assessing their practices and providing educational opportunities that are conducive for all learners.

\section{References}

Artiles, A.J., Kozleski, E., Trent, S., Osher, D. \& Ortiz, A. (2010). Justifying and explaining disproportionality, 1968-2008: A critique of underlying views of culture. Exceptional Children, 76, 279-299.

Artiles, A.J. \& Ortiz, A.A. (2002). English language learners with special education needs: Identification, assessment, and instruction. Washington, DC, and McHenry, IL: Center for Applied Linguistics and Delta System.

Artiles, A.J. \& Rueda, R. (2002, March-April). General guidelines for monitoring minority overrepresentation in special education. CASE Newsletter, 43, 5-6. Retrieved from http://www.nccrest.org/PDFs/ Artiles-Rueda.pdf.

Artiles, A.J., Rueda, R., Salazar, J. \& Higareda, I. (2005). Within-group diversity in minority disproportionate representation: English language learners in urban school districts. Exceptional Children, 71, 283-300.

Aud, S., Hussar, W., Kena, G., Bianco, K., Frohlich, L., Kemp, J. \& Tahan, K. (2011). The Condition of Education 2011 (NCES 2011-033). U.S. Department of Education, National Center for Education Statistics. Washington, DC: U.S. Government Printing Office.

Brown, M. (2007). Educating all students: Creating culturally responsive teachers, classrooms, and schools. Intervention in School \& Clinic, 43, 57-62. 
Burnette, J. (1998). Reducing the disproportionate representation of minority students in special education. ERIC/OSEP Digest, \#E566, ERIC Clearinghouse on Disabilities and Gifted Education, Council for Exceptional Children. Retrieved from http:// eric.ed.gov/ERICDocs/data/ericdocs2sql/content_ storage_01/0000019b/80/15/4e/26.pdf

CensusViewer (2010). Census 2010 and 2000 Interactive Map, Demographics, Statistics, Quick Facts. Retrieved November 7, 2012, from http://censusviewer.com/city/IL/Cicero

DataCenter (2012). Kids count. Retrieved November 10, 2012 from http://datacenter.kidscount.org/data/ bystate/stateprofile.aspx?state $=$ IL \&loc $=9948$

ePodunk.com (2008). Cook County, IL, ancestry and family history. Retrieved from http://www.epodunk. com/cgi-bin/genealogylnfo.php?loclndex $=6032$

Garson, D. (2007). Survey research. Retrieved from http:// faculty.chass.ncsu.edu/garson/PA765/survey.htm

Illinois State Board of Education (2007). Annual state report on special education performance (2006-2007). Retrieved from http://www.isbe.net/SPEC-ED/pdf_ reports/annual_performance_report06-07.pdf

National Association of State Directors of Special Education, Inc [NASDSE] (n.d.). Response to intervention, policy considerations and implementations. Retrieved from http://www.nasdse.org/ Portals/0/Documents/Download\%20Publications/ NASDSE_RtI.ppt\#16

National Association of State Directors of Special Education (NASDSE) \& Council of Administrators of Special Education (CASE) (2006, May). Response to intervention. Council for Exceptional Children. Retrieved from http://www.nasdse.org/ Portals/0/Documents/Download\%20Publications/ RtIAnAdministratorsPerspective1-06.pdf

National Education Association (NEA) \& National Association of School Psychologists (NASP) (2007). Truth in labeling: Disproportionality in special education, and disproportionality policy statement. Retrieved from http://www.nea.org/assets/docs/HE/ EW-TruthInLabeling.pdf

Nieto, S. \& Bode, P. (2008). Affirming diversity: The sociopolitical context of multicultural education $\left(5^{\text {th }}\right.$ ed.). Boston, MA: Allyn and Bacon.

Obringer, S.J. (1998, November). An improved model for evaluating minority and non-minority students with learning disabilities. Annual Meeting of MidSouth Educational Research Association, New Orleans, LA.

Ortiz, A. (1992, August). Assessing appropriate and inappropriate referral systems for LEP special education students. Focus on evaluation and measurement. Vol. 1-2. Proceedings of the National Research Symposium on Limited English Proficient Student Issues. Washington, DC (September 4-6, 1991).

Park, Y. \& Thomas, R. (2012). Educating English-Language learners with special needs: Beyond cultur- al and linguistic considerations. Journal of Education and Practice, 3, 52-58.

Perez, B. (1998). Sociocultural contexts of language and literacy. Mahwah, NJ: Lawrence Erlbaum.

Rueda, R. \& Windmueller, M. (2006). English language learners, LD, and overrepresentation: A multiple-level analysis. Journal of Learning Disabilities, 39, 99-107.

Samson, J.F. \& Lesaux, N.K. (2009). Language minority learners in special education: Rates and predictors of identification for services. Journal of Learning Disabilities, 42, 148-162. DOI: 10.1177 /0022219408326221

Schon, J., Shaftel, J. \& Markham, P. (2008). Contemporary issues in the assessment of culturally and linguistically diverse learners. Journal of Applied School Psychology, 24, 163-189. DOI:10.1080/15377900802089395

Shifrer, D., Muller, C. \& Callahan, R. (2011). Disproportionality and learning disabilities: Parsing apart race, socioeconomic status, and language. Journal of Learning Disabilities, 44, 246-257. DOI: 10.1177/0022219410374236

Shepherd, T.L., Linn, D. \& Brown, R.D. (2005, Spring). The disproportionate representation of English Language Learners for special education services along the border. Journal of Social and Ecological Boundaries, 1.1, 104-116.

Shin, H.B. \& Kominski, R.A. (2010). Language usage in the United States: 2007, American Community Survey Reports, ASC-12. Washington, DC: U.S. Census Bureau.

Skiba, R., Poloni-Staudinger, L., Gallini, S., Simmons, A. \& Feggins-Azziz, R. (2006). Disparate access: The disproportionality of African American students with disabilities across educational environments. Exceptional Children, 72, 411-424.

Sullivan, A. (2011). Disproportionality in Special Education identification and placement of English Language learners. Exceptional Children, 77, 317-334.

Warger, C. \& Burnette, J. (2000). Five strategies to reduce overrepresentation of culturally and linguistically diverse students in special education. Retrieved from ERIC/OSEP Digest \#E596, ERIC Clearinghouse on Disabilities and Gifted Education http:// www.ericdigests.org/2001-3/five.htm
Perspectives on disproportionate representation 